Number of pages: 19

Number of references: 38

Number of figures: 10

Number of tables: 1

\title{
Predicting discomfort from whole-body vertical vibration when sitting with an inclined backrest
}

Authors:

Bazil Basri and Michael J. Griffin

Affiliations:

Human Factors Research Unit

Institute of Sound and Vibration Research

University of Southampton

Southampton, SO17 1BJ

England

Corresponding author:

Professor Michael J. Griffin

Tel: +44 (0) 2380592277

Fax: +44 (0) 2380592927

Email: M.J.Griffin@soton.ac.uk 


\begin{abstract}
Current methods for evaluating seat vibration to predict vibration discomfort assume the same frequency weightings and axis multiplying factors can be used at the seat surface and the backrest irrespective of the backrest inclination. This experimental study investigated the discomfort arising from whole-body vertical vibration when sitting on a rigid seat with no backrest and with a backrest inclined at $0^{\circ}$ (upright), 30, $60^{\circ}$, and $90^{\circ}$ (recumbent). Within each of these five postures, 12 subjects judged the discomfort caused by vertical sinusoidal whole-body vibration (at frequencies from 1 to $20 \mathrm{~Hz}$ at magnitudes from 0.2 to $2.0 \mathrm{~ms}^{-2} \mathrm{r}$.m.s.) relative to the discomfort produced by a reference vibration ( $8 \mathrm{~Hz}$ at $0.4 \mathrm{~ms}^{-2}$ r.m.s.). With 8$\mathrm{Hz}$ vertical vibration, the subjects also judged vibration discomfort with each backrest condition relative to the vibration discomfort with no backrest. The locations in the body where discomfort was experienced were determined for each frequency at two vibration magnitudes. Equivalent comfort contours were determined for the five conditions of the backrest and show how discomfort depends on the frequency of vibration, the presence of the backrest, and the backrest inclination. At frequencies greater than about $8 \mathrm{~Hz}$, the backrest increased vibration discomfort, especially when inclined to $30^{\circ}, 60^{\circ}$, or $90^{\circ}$, and there was greater discomfort at the head or neck. At frequencies around 5 and $6.3 \mathrm{~Hz}$ there was less vibration discomfort when sitting with an inclined backrest.
\end{abstract}

Keywords: Backrest angle; whole-body vibration; ride comfort; prediction model. 


\section{INTRODUCTION}

The inclination of a seat backrest influences sitting comfort. In some limousines, aircraft, and ships, seats with backrests that incline from the vertical to the horizontal may be associated with luxury. However, in a transport environment, the inclination of the backrest will also influence the vibration transmitted to the body and the vibration discomfort experienced by passengers and by drivers. Procedures for predicting the discomfort associated with different backrest inclinations and different characteristics of vibration are needed so that seats can be optimised for comfort.

Vertical vibration is often dominant in transport. Studies of the discomfort caused by the wholebody vertical vibration of people seated with no backrests have shown a strong dependence on the frequency of the vibration (e.g., Miwa, 1967; Jones and Saunders, 1972; Dupuis et al., 1972; Griffin et al., 1982; Morioka and Griffin, 2006). Studies of physical responses (e.g., apparent mass, mechanical impedance, transmissibility) to whole-body vertical vibration when sitting with no backrest also show a strong dependence on the frequency of the vibration (e.g. Fairley and Griffin, 1989; Paddan and Griffin, 1988). Some similarities in the frequencydependence of subjective and physical responses suggest vibration discomfort is associated with physical responses of the body. For example, the seated body tends to be most sensitive to whole-body vertical acceleration around $5 \mathrm{~Hz}$, consistent with an apparent mass resonance around $5 \mathrm{~Hz}$ (e.g. Fairley and Griffin, 1989).

Studies of subjective responses to whole-body vertical vibration suggest the presence of an upright backrest increases discomfort at frequencies greater than the frequencies at which the body is most sensitive (e.g. Shoenberger and Harris, 1971; Oborne and Boarer, 1982). A similar influence of a backrest can be seen in the physical responses of the body. With a vertical backrest, a general trend for increased resonance frequencies and increased apparent mass at frequencies greater than the resonance has been reported, probably due to changes in the dynamic responses of the body arising from differences in the vibration transmission paths to the body and the body posture (Fairley and Griffin, 1989). The transmission of vertical seat vibration to the head is also changed by the addition of a backrest: fore-and-aft head motion has been reported to increase at frequencies up to $25 \mathrm{~Hz}$, with almost a doubling at the frequency of greatest transmissibility around $7 \mathrm{~Hz}$; vertical head motion showed a more distinct peak around $6 \mathrm{~Hz}$, and pitch head motion was increased at frequencies greater than principal resonance around $4 \mathrm{~Hz}$ (Paddan and Griffin, 1988).

With increasing inclination of a backrest, there is a systematic increase in the resonance frequency of the vertical apparent mass of seated people: from $5 \mathrm{~Hz}$ with a vertical backrest to 6.4 or $7.5 \mathrm{~Hz}$ with $30^{\circ}$ backrest inclination (e.g. Shibata and Maeda, 2009; Toward and 
Griffin, 2009), and to 7.0 or $9.4 \mathrm{~Hz}$ with maximum contact of the semi-supine body with a horizontal backrest (Huang and Griffin, 2008).

Studies of the subjective responses of seated people exposed to vertical vibration have been limited to upright backrests. Although there have been studies of the influence of backrest inclination on the discomfort caused by fore-and-aft vibration (Kato and Hanai, 1998; Basri and Griffin, 2011), current understanding is not sufficient to predict how the discomfort caused by whole-body vertical vibration depends on backrest inclination.

Current standards (BS 6841, 1987; ISO 2631-1, 1997) suggest the overall vibration discomfort of seated people can be predicted from an appropriate summation of the discomfort expected from vibration evaluated separately at the seat, the back, and the feet (i.e. multiple-input vibration). Frequency weightings and axis multiplying factors have been developed to reflect sensitivity to different frequencies and different directions of vibration at these locations. The 'weighted' accelerations are then combined, using the square-root of the sums of squares (r.s.s.) of the individual values, to predict the overall discomfort. This procedure was based on the assumption that the discomfort from multiple-input vibration could be predicted the same way that the discomfort of multiple-axis vibration can be predicted: using the r.s.s. method as opposed to using linear summation of all values, the greatest value (e.g. Griffin and Whitham, 1977; Shoenberger, 1988; Mistrot et al., 1990), or masking methods (Fothergill and Griffin, 1977). The method of summation ignores the influence of phase between inputs, although phase differences can contribute to discomfort (Jang and Griffin, 1999; 2000).

There is no clear provision in the standards for any adjustment of either the frequency weightings or the axis multiplying factors to allow for variations in the inclination of backrests. However, it has been reported that backrest inclination changes frequency sensitivity to $x$-axis vibration of backrests (Kato and Hanai, 1998; Basri and Griffin, 2011) and sensitivity to vertical seat vibration (Basri and Griffin, 2012). The frequency weighting $W_{c}$, recommended in the standards for evaluating the $x$-axis vibration of the back, was based on the equivalent comfort contours of 12 male subjects exposed to fore-and-aft vibration of an upright backrest while sitting on a stationary seat pan with a stationary footrest (Parsons et al., 1982). Application of the $W_{c}$ weighting when evaluating the $x$-axis vibration of inclined backrests tends to overestimate vibration discomfort at low frequencies (less than $8 \mathrm{~Hz}$ ) and underestimate vibration discomfort at high frequencies (Kato and Hanai, 1998; Basri and Griffin, 2011). Recently, equivalent comfort contours have been determined for 12 male subjects exposed to vertical vibration of a seat pan while sitting with stationary inclined backrests $\left(0^{\circ}, 30^{\circ}, 60^{\circ}\right.$ and $90^{\circ}$ from vertical) and a stationary footrest (Basri and Griffin, 2012). With increasing inclination of the backrest, the proportion of body weight supported by the vibrating seat pan decreased and vibration discomfort reduced at all frequencies. The reduction in discomfort was more 
prominent (by about $6 \mathrm{~dB}$ ) with greater inclinations of the backrest $\left(60^{\circ}\right.$ and $\left.90^{\circ}\right)$ and at frequencies less than $8 \mathrm{~Hz}$. The findings imply that the axis multiplying factor for vertical seat vibration (1.0 in the current standards) should reduce as backrest inclination increases.

The study reported here investigated the influence of backrest inclination on the discomfort of seated people exposed to whole-body vertical vibration (i.e., vertical vibration at the seat, the back, and the feet). This made it possible to examine the suitability of current procedures for evaluating vibration with respect to the discomfort caused by multiple-input vibration. It was hypothesised that, with increasing backrest inclination, there would be a change in the frequency-dependence of discomfort caused by backrest vibration, and a change in the relative sensitivity to seat vibration. Consequently, the frequency dependence of the discomfort of seated people arising from whole-body vertical vibration would change with backrest inclination. It was also hypothesised that the r.s.s. procedure would predict the difference in vibration discomfort experienced when sitting upright with or without a backrest. It was expected that current frequency weightings and axis multiplying factors for seat vibration and back vibration would not provide optimum predictions of variations in vibration discomfort when sitting with different inclinations of the backrest.

\section{METHOD}

\section{$2.1 \quad$ Test rig}

An aluminium frame supporting a wooden seat pan, backrest, footrest and, where appropriate, support for the lower leg, was constructed and mounted securely to the platform of a vertical vibrator (Figure 1). The backrest was adjustable to inclinations of $0^{\circ}, 30^{\circ}, 60^{\circ}$, or $90^{\circ}$ (fully recumbent). The footrest was inclined $30^{\circ}$ from horizontal. The dimensions of the apparatus were determined based on a comfortable sitting posture for a $50^{\text {th }}$ percentile British male aged 19 to 45 years (Pheasant, 1990). The positions were achieved using an $\mathrm{H}$-point manikin with knee and ankle angles set to $120^{\circ}$ and $100^{\circ}$, respectively (Rebiffé, 1969). With the backrest inclined at $90^{\circ}$, subjects lay flat on their backs with their calves supported. A rigid headrest was provided, except when there was no backrest and when the backrest was upright. The supports for the pelvic area (buttocks and thighs), back, head, and calves were covered with 1-mm thick neoprene rubber to provide some friction between the supports and the body.

Figure 1 ABOUT HERE 


\subsection{Signal generation and acquisition}

The vibration stimuli were produced using a hydraulic vibrator capable of 1-meter peak-topeak displacement in the vertical direction. The stimuli were generated and sampled using HVLab Signal Processing Toolbox in Matlab (version R2009) and output via a digital-toanalogue converter (NI 6211) at 512 samples per second.

The acceleration of the platform was monitored using single-axis piezo-resistive accelerometers (Entran Model EGCSY-240D-10) attached to the platform. Signals from the accelerometers were low-pass filtered at $50 \mathrm{~Hz}$ and then sampled at 512 samples per second.

\subsection{Vibration stimuli}

All vibration stimuli were 5-second sinusoids with 1-s cosine-tapering at the start and end.

The subjects were requested to judge 'vibration discomfort' (i.e., their feelings about the vibration alone; Griffin, 1990). In Part 1, subjects judged the discomfort caused by various frequencies and magnitudes of vertical whole-body vibration within the same sitting condition: they compared the discomfort caused by 'test' vibrations relative to a 'reference' vibration (i.e. $8 \mathrm{~Hz}$ at $0.4 \mathrm{~ms}^{-2}$ r.m.s.). The 'test' vibrations were from an array of 14 frequencies (the preferred one-third octave centre frequencies from 1 to $20 \mathrm{~Hz}$ ) and 7 magnitudes (separated by $3 \mathrm{~dB}$ steps). The range of magnitudes was such that the same $W_{\mathrm{b}}$ frequency-weighted acceleration was used at all frequencies (e.g. 0.5 to $2 \mathrm{~ms}^{-2}$ r.m.s. at $1 \mathrm{~Hz}$, and 0.2 to $0.8 \mathrm{~ms}^{-2}$ r.m.s. at $20 \mathrm{~Hz}$ ).

In Part 2, subjects judged the discomfort caused by the same seven levels of $8-\mathrm{Hz}$ 'test' vibration while sitting in the test condition (sitting as in Part 1) relative to a 'reference' vibration while sitting in a reference condition (i.e., $0.4 \mathrm{~ms}^{-2}$ r.m.s. at $8 \mathrm{~Hz}$, sitting in an upright posture with no backrest).

In Part 3, the test stimuli were two magnitudes of vertical seat vibration at each frequency: the middle magnitudes and the greatest magnitudes used in Part 1.

\section{$2.4 \quad$ Procedure}

The experiment was conducted in five sessions corresponding to the five backrest conditions (i.e. no backrest, and the backrest inclined at $0^{\circ}, 30^{\circ}, 60^{\circ}$, and $90^{\circ}$ ). Each subject completed all five sessions within three days, with one session on the first day followed by two sessions on the second day and the remaining two sessions on the final day. Each session lasted less than 45 minutes. The order of the session was balanced across subjects. To confirm understanding of the magnitude estimation method used in the experiment, subjects had a short exercise judging the apparent length of lines relative to the length of a reference line. 
They also practiced judging vibration before commencing the experiment on their first day. On the second and final day, subjects were provided with a 5- to 10-minute break between sessions for them to feel sufficiently rested before embarking on the second session.

Each session comprised three parts corresponding to three psychophysical tests:

Part 1: Equivalent comfort contours within backrest condition,

Part 2: Relative discomfort between backrest conditions, and

Part 3: Location of discomfort.

In Part 1, subjects were requested to sit on the seat pan with their backs leaning comfortably against the backrest. To ensure a similar body posture in all subjects, they were asked to rest their hands on their laps, or hold their hands together on their stomach when the backrest was inclined to $60^{\circ}$ or $90^{\circ}$ (recumbent). In the no backrest condition and in the upright backrest $\left(0^{\circ}\right)$ condition, there was no support for the head and subjects were requested to sit with a comfortable upright posture throughout. They were asked to maintain contact between their back and the upright backrest. For backrest inclinations of $0^{\circ}$ (upright), $30^{\circ}$, and $60^{\circ}$, the feet were supported, whereas when recumbent (at $\left.90^{\circ}\right)$, the calves were supported.

In Part 2, subjects were requested to sit in an upright posture with no backrest (for the reference condition) and then adjust their posture to sit in the test condition (sitting as in Part 1). The stimuli were presented only when the subjects had adopted the required posture and they were ready. The presentation of both stimuli was repeated whenever requested by the subjects. This part was omitted for the session with no backrest.

In Part 3, subjects were required to sit as in Part 1.

In all tests, subjects were required to close their eyes during presentations of the stimuli to avoid seeing their body movement. They wore headphones presenting a masking white noise at $65 \mathrm{~dB}(\mathrm{~A})$. The experimenter and subjects were provided with separate emergency stop buttons.

\subsubsection{Equivalent comfort contours within backrest condition: Part 1}

In Part 1, the 5-s reference vibration was followed by a 2-s pause and then a 5-s test vibration. Subjects provided a magnitude estimate for the discomfort caused by each test vibration assuming the magnitude estimate of the discomfort caused by the reference vibration $(8-\mathrm{Hz}$ at $0.4 \mathrm{~ms}^{-2}$ r.m.s.) was 100 . The 98 pairs of vibration stimuli, comprising the reference vibration paired with each of the test vibrations (of differing magnitude and frequency) were presented in a different randomised order to each subject over a period of approximately 30 minutes. 


\subsubsection{Relative discomfort between backrest conditions: Part 2}

In Part 2, subjects judged the discomfort caused by $8-\mathrm{Hz}$ test vibration in the same posture as in Part 1 relative to the discomfort caused by $8-\mathrm{Hz} 0.4 \mathrm{~ms}^{-2}$ r.m.s. vibration when sitting upright with no backrest (the common reference condition). They judged the same seven magnitudes of $8-\mathrm{Hz}$ test vibration presented in Part 1 . The vibration stimuli were presented in a different random order for each subject over a period of 3 to 5 minutes.

\subsubsection{Location of discomfort: Part 3}

In Part 3, subjects indicated the location in their body where they felt the most vibration discomfort using a body map placed in front of them. They were exposed to 28 vibration stimuli (the middle magnitude and the greatest magnitude at each of the 14 frequencies in Part 1) presented in randomised order over a period of approximately 5 minutes.

\subsection{Subjects}

Using a within-subject experimental design, 12 healthy male subjects participated in all five sessions of the experiment. Subjects had a mean age of 26 years (SD: 2.1), a mean stature of $1.76 \mathrm{~m}$ (SD: 9.3), and a mean weight of $70.5 \mathrm{~kg}$ (SD: 15.3). Subjects were students and staff of the University of Southampton with no history of any serious illness, injury, or disability that might affect their vibration sensations.

The experiment was approved by the Human Experimentation Safety Ethics Committee of the Institute of Sound and Vibration Research at the University of Southampton. All subjects gave their voluntary consent prior to the start of their first session on each day.

\subsection{Predicted discomfort}

According to current standards (BS 6841: 1987 and ISO 2631-1:1997), the discomfort arising from exposure to whole-body vertical vibration can be predicted from acceleration at the seat, the back and the feet (Figure 2). The prediction employs the square-root of the sums-ofsquares (r.s.s.) of the weighted r.m.s. accelerations using frequency weightings and axis multiplying factors for each direction and location of vibration to yield a 'single value' (i.e. overall weighted acceleration), termed the 'overall ride value' or 'vibration total value', indicative of the likely discomfort.

\section{Figure 2 ABOUT HERE}

Two aspects of the prediction procedure were examined: the weightings for frequency and axis (i.e., frequency weightings and axis multiplying factors) and the method of combining vibration at more than one location (i.e., r.s.s.) 


\section{RESULTS}

\subsection{Equivalent comfort contours within backrest condition (Part 1)}

\subsubsection{Rate of growth of discomfort, $n$, and constant, $k$}

The magnitude estimate of vibration discomfort, $\psi$, caused by the vibration magnitude, $\varphi$, at each frequency, $f$, are assumed to be related by a power law (Stevens, 1975):

$$
\Psi=k \varphi^{n}
$$

so,

$$
\log _{10} \psi=n \log _{10} \varphi+\log _{10} k
$$

Individual values for the rate of growth of discomfort, $n$, and the constant, $k$, were determined from the slopes and intercepts of linear least squares regressions between $\log _{10} \psi$ and $\log _{10} \varphi$ at each frequency.

The rate of growth of discomfort, $n$, caused by the vertical vibration within each of the five backrest conditions (no backrest and backrest inclined at $0^{\circ}, 30^{\circ}, 60^{\circ}$ and $90^{\circ}$ ) was strongly dependent on the frequency of vibration (Figure 3; $p<0.001$, Friedman). However, the rate of growth of discomfort did not differ across backrest conditions at any frequency $(p=0.065$, Friedman).

\section{Figure 3 ABOUT HERE}

The constant, $k$, within each of the five backrest conditions was also strongly dependent on the frequency of vibration (Figure $4 ; p<0.01$, Friedman). The constant, $k$, was dependent on backrest inclination at $3.15,4,5,16$ and $20 \mathrm{~Hz}(p<0.0036$, Friedman).

\section{Figure 4 ABOUT HERE}

\subsubsection{Equivalent comfort contours within backrest conditions}

Within each backrest condition, individual equivalent comfort contours were calculated at seven sensation magnitudes (from $\psi=50$ to 200 , relative to 100 with $0.40 \mathrm{~ms}^{-2}$ r.m.s. of $8-\mathrm{Hz}$ vibration with the same backrest condition) using Equation 1 and individual $n$ and $k$ values at each frequency. Median equivalent comfort contours were constructed from the 12 individual equivalent comfort contours at each of these seven sensation magnitudes.

The dependence of the constant, $k$, on the frequency of vibration caused the equivalent comfort contours to vary systematically with the frequency of vibration, and the dependence 
of the rate of growth of discomfort, $n$, on the frequency of vibration caused the shapes of the equivalent comfort contours to vary systematically with the magnitude of vibration (Figure 5).

Table 1 and Figure 5 ABOUT HERE

\subsection{Relative discomfort between backrest conditions (Part 2)}

For each backrest condition, the equivalent comfort contours for each subject were rescaled to the sensation magnitude of the common reference (i.e. the discomfort caused by $0.4 \mathrm{~ms}^{-2}$ r.m.s. $8-\mathrm{Hz}$ vibration when sitting with no backrest), using individual $n$ and $k$ values obtained with the respective backrest inclinations. The medians of these twelve individual 'rescaled' equivalent comfort contours were determined for each backrest condition to show the relative discomfort between backrest conditions (Figure 6). The equivalent comfort contours show the r.m.s. acceleration required at the platform at each frequency for each backrest condition to cause similar discomfort to that caused by the common reference vibration.

Figure 6 ABOUT HERE

The vibration magnitude required at any frequency for the discomfort to be equivalent to that caused by the common reference vibration depended on the backrest condition at all frequencies greater than $3.15 \mathrm{~Hz}$, excluding $8 \mathrm{~Hz}(p<0.05$, Friedman: Figure 6a). After excluding the condition without a backrest, the vibration magnitude required at each of the six frequencies greater than $5 \mathrm{~Hz}$, excluding $8 \mathrm{~Hz}$, was still significantly dependent on backrest inclination ( $p<0.05$, Friedman). After adjusting for multiple comparisons $(0.05 / 6 \approx 0.008)$, there were no significant differences at any of these frequencies in the vibration magnitudes required between sitting upright with no backrest and sitting with an upright backrest $(p>0.008$, Wilcoxon: Figure $6 \mathrm{~b}$ ), or between sitting with the backrest inclined at $60^{\circ}$ and fully reclined ( $p>0.008$, Wilcoxon). With the backrest inclined to $30^{\circ}$, the required vibration magnitude was significantly less than with the upright backrest at $20 \mathrm{~Hz}$ ( $p=0.002$; Wilcoxon; Figure 6c). With the backrest inclined to $60^{\circ}$, the required vibration magnitude was significantly less at 16 and $20 \mathrm{~Hz}$, and significantly greater at 5 and $6.3 \mathrm{~Hz}$ than with the upright backrest $(p<0.008$, Wilcoxon; Figure $6 \mathrm{~d}$ ). With the fully reclined backrest, the vibration magnitude required was significantly less at 16 and $20 \mathrm{~Hz}$ and significantly greater at $5 \mathrm{~Hz}$ than with the upright backrest $(p<0.008$, Wilcoxon; Figure 6e).

\subsection{Location of discomfort (Part 3)}

With all frequencies and magnitudes of vibration and all backrest conditions, subjects generally felt discomfort in their back, buttocks, or thighs: the body parts in which the greatest proportions of their body weight were in contact with, and supported by, the vibrating surfaces 
(Figure 7). However, the number of subjects reporting discomfort in either their head or neck varied with frequency when sitting with inclined backrests $\left(30^{\circ}, 60^{\circ}\right.$ and $\left.90^{\circ}\right)$ and exposed to the middle and greatest magnitude test stimuli ( $p<0.001$, Cochran's $Q)$.

The number of subjects reporting discomfort in either their head or neck depended on backrest condition at 10,16 and $20 \mathrm{~Hz}$ when exposed to the middle magnitude test stimuli $(p<0.05$, Cochran's $Q$ ), and at $5 \mathrm{~Hz}$ and all frequencies greater than $10 \mathrm{~Hz}$ when exposed to the greatest magnitude test stimuli ( $p<0.01$, Cochran's $Q$ ). There were also changes between sitting with no backrest and sitting with any of the inclined backrests $\left(30^{\circ}, 60^{\circ}\right.$ or $\left.90^{\circ}\right)$ at $20 \mathrm{~Hz}$ when exposed to the middle magnitude test stimuli $(p<0.008$, McNemar) and at 16 and $20 \mathrm{~Hz}$ when exposed to the greatest magnitude test stimuli $(p<0.008$, McNemar).

Figure 7 ABOUT HERE

\section{DISCUSSION}

\subsection{Effect of the backrest}

The presence of the upright backrest exposed the subjects to an additional source of excitation along the z-axis of the back. Although this additional input did not greatly change the acceleration required to produce similar overall discomfort to that with no backrest (Figure 6b), there was a tendency for the backrest to increase perception of vibration in the upper-body (upper back, shoulder, neck and head: Figure $7 \mathrm{a}$ and $7 \mathrm{~b}$ ) and increase discomfort at frequencies greater than $8 \mathrm{~Hz}$ (Figure 6). Previous studies have produced equivalent comfort contours for whole-body vertical vibration of seated people with a backrest (Shoenberger and Harris, 1971; Oborne and Boarer, 1982, Donati et al., 1983, Corbridge and Griffin, 1986) and without a backrest (Miwa, 1967; Jones and Saunders, 1972; Dupuis et al., 1972; Griffin, 1976; Griffin et al., 1982; Morioka and Griffin, 2006), as shown in Figure 8. Differences between contours obtained with and without backrest seem to become apparent at frequencies greater than about $8 \mathrm{~Hz}$ : with a backrest, the contours tend to be lower, indicating a lower magnitude of vibration is required to cause similar discomfort (i.e. greater discomfort with a backrest).

\section{Figure 8 ABOUT HERE}

At low frequencies the presence of the full upright backrest did not seem to cause any significant change in discomfort. At low frequencies a backrest may support the back and prevent parts of the body pitching forward and backward during oscillation. Although this would be expected to reduce discomfort, there is little evidence of greater magnitudes being required to cause discomfort when sitting with the backrest in the present study with vertical excitation. 
An upright backrest tends to stiffen the body: the resonance frequencies in the vertical apparent mass measured at the seat surface increase when sitting with a rigid upright backrest: from around $5 \mathrm{~Hz}$ without a backrest to $5.5 \mathrm{~Hz}$ with a backrest (Toward and Griffin, 2009). The backrest therefore tends to increase the apparent mass at frequencies greater than the principal resonance frequency and reduce the apparent mass at frequencies less than the principal resonance. It has also been reported that a full rigid upright backrest (contacting the back, lumbar, and pelvis region) increase apparent mass at all frequencies from the principal resonance frequency to around $20 \mathrm{~Hz}$ (e.g. Wang et al., 2004). This is consistent with increased transmission of vibration to the body and the trend for increased discomfort at high frequencies with the upright backrest used in the present study.

\subsection{Effect of backrest inclination}

With the inclined backrests $\left(30^{\circ}, 60^{\circ}\right.$ and $\left.90^{\circ}\right)$, there is a clear trend for greater discomfort at frequencies greater than $8 \mathrm{~Hz}$, and less discomfort at $5 \mathrm{~Hz}$ and $6.3 \mathrm{~Hz}$ (although only very slightly less with $30^{\circ}$-inclination), than with an upright backrest (Figure 6c, 6d and 6e). In addition to vibration at the seat surface, subjects were exposed to increasing vibration in the $x$-axis of the back as the inclination of the backrest increased. The frequencies of $x$-axis vibration of the back causing greatest discomfort shift from below $8 \mathrm{~Hz}$ to around 10 or 12.5 $\mathrm{Hz}$ as a backrest is inclined; there is reduced discomfort at frequencies less than 10 or 12.5 $\mathrm{Hz}$ with inclined backrests (at $30^{\circ}, 60^{\circ}$ and $90^{\circ}$ ) and 30 to $40 \%$ greater acceleration is required at frequencies between 4 to $8 \mathrm{~Hz}$ to cause similar discomfort to that with an upright backrest (Basri and Griffin, 2011; Basri and Griffin, 2012). This is consistent with a greater contribution to discomfort from $x$-axis vibration of the back than vertical seat vibration.

There is evidence of an increase in the resonance frequency of the vertical apparent mass measured at the seat surface as the inclination of a backrest increases: from 5 or $5.5 \mathrm{~Hz}$ with an upright backrest to 6.5 or $7.5 \mathrm{~Hz}$ with a backrest inclined by $30^{\circ}$ (Shibata and Maeda, 2009; Toward and Griffin, 2009). An increase in the resonance frequency of the vertical apparent mass on the seat as a backrest inclines is consistent with a greater percentage of the body mass being supported by the inclined backrest, and the backrest becoming a more important source of vibration. This may explain why the region of greatest sensitivity to acceleration increased from $5 \mathrm{~Hz}$ with an upright backrest to a greater frequency with the inclined backrests.

With the fully reclined backrest $\left(90^{\circ}\right)$, the frequency-dependence of the equivalent comfort contours obtained in the present study are broadly similar to thresholds and equivalent sensation contours reported in previous studies (e.g., Miwa and Yonekawa, 1969; Szameitat and Dupuis, 1976; Miwa et al., 1984; Yonekawa et al., 1999; Gibson, 1978: Figure 9). The 
contours reported by Gibson (1978) indicate less discomfort at high frequencies, but subjects lay on a stretcher with undefined dynamic properties that may have reduced the transmission of high-frequency vibration to the body. Increased discomfort at frequencies greater than $8 \mathrm{~Hz}$ with the fully reclined backrest may be associated with resonance frequencies in the vertical apparent mass of the semi-supine body (at 7 or $9.4 \mathrm{~Hz}$ ) when lying with maximum contact with a horizontal flat backrest (Huang and Griffin, 2008) and the resonances in the transmission of vertical vibration from a back support to the sternum (between 6 and $12 \mathrm{~Hz}$ ) in the same posture (Huang and Griffin, 2009).

\section{Figure 9 ABOUT HERE}

Increased discomfort at high frequencies when using a backrest, particularly the inclined backrests at frequencies greater than $10 \mathrm{~Hz}$ (Figure 6a), might also have arisen from increased discomfort in the head and neck, as reported by many subjects (Figure 7). Paddan and Griffin (1988) reported the addition of a vertical backrest increased the vibration of the head in several directions during vertical excitation of a seat. Fore-and-aft motion of the head increased at frequencies up to $25 \mathrm{~Hz}$ (with almost a doubling at the frequency of greatest transmissibility around $7 \mathrm{~Hz}$ ), vertical motion of the head showed a more distinct peak at $6 \mathrm{~Hz}$, and pitch head motion was increased at frequencies greater than the principal resonance.

\subsection{Comfort prediction model}

The study allows three aspects of the prediction model used in current standards to be tested: the frequency weightings $\left(W_{\mathrm{i}}\right)$, the axis weightings $\left(k_{\mathrm{i}}\right)$, and the method of combining inputs (root-sums-of-squares, r.s.s.).

The experiment has revealed the acceleration of the vibrator platform $\left(a_{p}\right)$ required at each frequency when sitting with each backrest inclination to cause the same discomfort as when sitting with no backrest (Figure 6a). If the weighting and combination methods are suitable, they should yield the same 'overall ride values' at all frequencies and with all backrest conditions (i.e. a value of $0.4 \mathrm{~ms}^{-2}$ r.m.s., the magnitude of the $8-\mathrm{Hz}$ reference motion), as indicated by the reference line in Figure 10. When sitting with no backrest, there were three component ride values (i.e. $a_{z \text {-seat }}\left(\right.$ or $a_{\mathrm{p}}$ ), $a_{\text {x-feet }}\left(\right.$ i.e., $a_{\mathrm{p}} \sin \phi$ ), and $a_{z \text {-feet }}\left(\right.$ i.e., $a_{\mathrm{p}} \cos \phi$ )) from the vibration at two input locations (i.e., at the seat and at the footrest inclined at an angle $\phi$ ) (Figure 10a). When sitting with an inclined backrest, additional component ride values arise from vibration in the $x$-axis at the back $\left(a_{x \text {-back }}\left(\right.\right.$ i.e.,,$\left.\left.a_{\mathrm{p}} \sin \theta\right)\right)$ and the $z$-axis at the back $\left(a_{z \text {-back }}\right.$ (i.e., $\left.a_{\mathrm{p}} \cos \theta\right)$ ). With the upright backrest $\left(\theta=0^{\circ}\right)$, there was no component in the $x$-axis of the back (Figure 10b). 


\subsubsection{Frequency weightings}

The currently standardised procedure for evaluating whole-body vertical vibration provides a credible prediction of discomfort when there is no backrest, as seen in Figure 10a. However, when using a backrest there were less satisfactory predictions of overall discomfort. With the upright backrest, the prediction model overestimated the contribution from low-frequency zaxis vibration of the backrest (at frequencies less than about $4 \mathrm{~Hz}$ ). The overestimation of discomfort is more marked with greater inclinations of the backrest (to $30^{\circ}$ and $60^{\circ}$ ). As mention earlier, with inclined backrests there is evidence of greater sensitivity to $x$-axis vibration of the back at frequencies greater than $8 \mathrm{~Hz}$ and less sensitivity at lower frequencies compared to an upright backrest (Kato and Hanai, 1998; Basri and Griffin, 2011). This suggests the evaluation of $x$-axis vibration on inclined backrests with the $W_{c}$ frequency weighting could have contributed to an overestimation of the discomfort caused by frequencies less than about $8 \mathrm{~Hz}$ and underestimation of the discomfort caused by frequencies greater than $8 \mathrm{~Hz}$ (Figure 10c-e).

A $W_{\mathrm{j}}$ weighting is recommended in ISO 2631-1 (1997) for evaluating vertical vibration experienced by recumbent people. This weighting (with a gain of approximately 0.5 between 1 and $2 \mathrm{~Hz}$ rising to a gain of approximately unity from 5 to $80 \mathrm{~Hz}$ ) is used on vibration beneath the pelvis and, "when there is no soft pillow", on vibration beneath the head. In the present study the vibration beneath the head was the same as the vibration beneath the pelvis, but Figure 7 suggest that vibration of the head was only a dominant source of discomfort at 16 and $20 \mathrm{~Hz}$. At lower frequencies, vibration experienced in the back, buttocks, and thighs was more important.

\subsubsection{Axis weightings}

With increasing inclination of the backrest, there was increased sensitivity to vibration of the backrest, so that according to the standards it eventually became a more important source of discomfort than vertical vibration at the ischial tuberosities. With the fully reclined backrest (i.e., recumbent), the predicted discomfort was greater than the reference value at frequencies between $2.5 \mathrm{~Hz}$ and $8 \mathrm{~Hz}$, due to the frequency weighting $W_{c}$ for backrest vibration, as shown in Figure 10e. The frequency-dependence of overall discomfort with the fully reclined backrest would have been predicted better if the frequency weighting for $x$-axis vibration of the back (the dominant source of discomfort) was improved as suggested above (i.e. reduced sensitivity to vibration at frequencies less than $8 \mathrm{~Hz}$ and increased sensitivity to vibration at frequencies greater than $8 \mathrm{~Hz}$ ). 


\subsubsection{Combination method}

The component ride values were calculated from the accelerations $a_{p}$, at the seat, the back, and the feet, using the frequency weightings $W_{\mathrm{i}}(f)$ and axis multiplying factors $k_{\mathrm{j}}$ as defined in British Standard 6841 (1987): vertical seat $\left(W_{\mathrm{b}}, k=1\right), x$ - and $z$-axis of the back $\left(W_{\mathrm{c}}, k=0.8\right.$ and $W_{\mathrm{d}}, k=0.4$ respectively), $x$ - and $z$-feet $\left(W_{\mathrm{b}}, k=0.25\right.$ and $W_{\mathrm{b}}, \mathrm{k}=0.4$ respectively). International Standard 2631-1 (1997) recommends similar weightings except $W_{\mathrm{k}}$ is substituted for $W_{\mathrm{b}}$ and $W_{\mathrm{j}}$ is introduced for vertical vibration beneath the pelvis and head when recumbent. Three combination methods were tested: linear summation of component ride values, root-sums-ofsquares (r.s.s.) of component ride values, and use of only the greatest component ride value.

$$
\begin{gathered}
a=\left(\left(k_{\text {seat }} \times a_{\text {seat }}(f) \cdot W_{\text {seat }}(f)\right)^{\alpha}+\left(k_{\text {back }} \times a_{\text {back }}(f) \cdot W_{\text {back }}(f)\right)^{\alpha}+\left(k_{\text {feet }} \times a_{\text {feet }}(f) \cdot W_{\text {feet }}(f)\right)^{\alpha}\right)^{1 / \alpha} \\
\alpha=1 \text { : linear summation } \\
\alpha=2 \text { : root-sums-of-squares, r.s.s. }
\end{gathered}
$$$$
a=\max \left(\left(k_{\text {seat }} \times a_{\text {seat }}(f) \cdot W_{\text {seat }}(f)\right),\left(k_{\text {back }} \times a_{\text {back }}(f) \cdot W_{\text {back }}(f)\right),\left(k_{\text {feet }} \times a_{\text {feet }}(f) \cdot W_{\text {feet }}(f)\right)\right)
$$

With no backrest, there is no clear difference between the three combination methods (Figure 10a): all methods produce a value that is similar at all frequencies (three parallel and almost flat contours across the frequency range). The linear summation method produced higher values than the other methods as a result of taking a larger proportion of the vibration at the feet. This may be inconsistent with the subjective judgements of the location of discomfort because discomfort at the feet seems to have been negligible, particularly at low frequencies (see Figure 7a).

With the upright backrest, the overall ride values produced by the three combination methods differ at frequencies less than about $4 \mathrm{~Hz}$ (Figure 10b). When using only the greatest component (i.e. vertical seat vibration), the contour is flatter, suggesting it may be adequate to predict discomfort. Compared to the condition with no backrest, the inclusion of the z-axis vibration of the back in the prediction method may have caused an overestimation of discomfort at low frequencies when using both the linear summation method and the r.s.s. summation method. With no noticeable difference in the location of principal discomfort at low frequencies (Figure $7 \mathrm{a}$ and $7 \mathrm{~b}$ ), the use of the current weightings (frequency weighting $W_{\mathrm{d}}$ and axis multiplying factor $k=0.4$ ) for evaluating $z$-axis vibration of a vertical backrest with the r.s.s. combination method may not be optimum at frequencies less than $4 \mathrm{~Hz}$.

With inclined backrests, the predicted discomfort was generally less than the discomfort experienced by subjects (i.e., less than the reference value) at frequencies greater than about $10 \mathrm{~Hz}$. In these postures the discomfort was predominantly caused by sensations in the head, whereas with the upright backrest the vibration of the head was less important (Figure 7). It 
seems that as a backrest is reclined there is increased transmission of vibration to the head and that this is not reflected in the current use of frequency weightings and axis multiplying factors.

The application of the findings of this study should recognise that other factors may influence the dependence of vibration discomfort on the frequency of vibration and the inclination of a backrest. For example, differences between subjects (including the extremes of age, gender, body size, or fitness beyond those included in the study), clothing, and activities may modify the discomfort caused by whole-body vibration.

\section{CONCLUSIONS}

Currently standardised procedures for evaluating vibration (i.e., frequency weightings, axis weightings, and root-sums-of-squares summation) provide useful predictions of the discomfort caused by vertical seat vibration. However, when discomfort is influenced by the vibration of inclined backrests the predictions overestimate vibration discomfort at frequencies around 5 and $6.3 \mathrm{~Hz}$ and underestimate vibration discomfort at frequencies greater than $8 \mathrm{~Hz}$.

With an upright backrest, the current standard procedure overestimates discomfort caused by low-frequency z-axis vibration of the back (at frequencies less than about $2 \mathrm{~Hz}$ ). With a backrest inclined to $30^{\circ}$ or $60^{\circ}$, less weight is supported at the seat and more weight is supported at the back. It seems that the $W_{c}$ weighting for backrest vibration is then not optimum for evaluating vibration in the $x$-axis of the back.

\section{ACKNOWLEDGEMENT}

The authors are grateful for the support from the Ministry of Higher Education of Malaysia and Universiti Teknikal Malaysia, Melaka. The authors also wish to thank Dr Chris Lewis and Dr Miyuki Morioka for providing software used to control the experiment.

\section{REFERENCES}

Basri, B. and Griffin, M.J., 2011. The vibration of inclined backrests: perception and discomfort of vibration applied normal to the back in the $x$-axis of the body. Journal of Sound and Vibration, 330, 4646-4659.

Basri, B. and Griffin, M.J., 2012. Equivalent comfort contours of vertical seat vibration: effect of vibration magnitude and backrest inclination. Ergonomics, 55 (8), 909-922.

British Standards Institution BS 6841, 1987. Guide to measurement and evaluation of human exposure to whole-body mechanical vibration and repeated shock.

Corbridge, C. and Griffin, M.J., 1986. Vibration and comfort: vertical and lateral motion in the range 0.5 to $5.0 \mathrm{~Hz}$. Ergonomics, 29 (2), 249-272. 
Donati, P., Grosjean, A., Mistrot, P. and Roure, L., 1983. The subjective equivalence of sinusoidal and random whole-body vibration in the sitting position (an experimental study using the 'floating reference vibration' method). Ergonomics, 26 (3), 251-273.

Dupuis, H., Hartung, E. and Louda, L., 1972. The effect of random vibrations of a limited frequency band compared with sinusoidal vibrations, on human beings. Royal Aircraft Establishment, Library Translation No 1603, Ministry of Defence Farnborough, Hants.

Griffin, M.J. and Whitham, E.M., 1977. Assessing the discomfort of dual-axis whole-body vibration. Journal of Sound and Vibration, 54 (1), 107-116.

Griffin, M.J., 1976. Subjective equivalence of sinusoidal and random whole-body vibration. Journal of Acoustical Society of America, 60 (5), 1140-1145.

Griffin, M.J., Whitham, E.M. and Parsons, K.C., 1982. Vibration and comfort I. Translational seat vibration. Ergonomics, 25(7), 603-630.

Griffin, M.J., 1990. Handbook of Human Vibration. Elsevier Academic Press, London.

Fairley, T.E. and Griffin, M.J., 1989. The apparent mass of the seated human body: vertical vibration. Journal of Biomechanics, 22 (2), 81-94.

Fothergill, L.C. and Griffin, M.J., 1977. The evaluation of discomfort produced by multiple frequency whole-body vibration. Ergonomics, 20 (3), 263-276.

Gibson PDG 1978. The sensitivity of supine stretcher-borne human subjects to vibrations in three translational and two rotational modes. MIRA Report No K13010.

Huang, Y. and Griffin, M.J., 2008. Nonlinear dual-axis biodynamic response of the semi-supine human body during vertical whole-body vibration. Journal of Sound and Vibration, 312 (1-2), 296-315.

Huang, Y. and Griffin, M.J., 2009. Nonlinearity in apparent mass and transmissibility of the supine human body during vertical whole-body vibration. Journal of Sound and Vibration, 324 (1-2), 429-452.

Jang, H. -K. and Griffin, M.J., 1999. The effect of phase of differential vertical vibration at the seat and feet on discomfort. Journal of Sound and Vibration, 223 (5), 785-794.

Jang, H. -K. and and Griffin, M.J., 2000. Effect of phase, frequency, magnitude and posture on discomfort associated with differential vertical vibration at the seat and feet. Journal of Sound and Vibration, 229 (2), 273-286.

Jones, A.J. and Saunders, D.J., 1972. Effects of postural and methodological changes on equal comfort contours for whole-body, vertical, sinusoidal vibration. Applied Acoustics, 5, 279-299.

International Organization of Standardization ISO 2631-1, 1997. Mechanical vibration and shock - evaluation of human exposure to whole-body vibration - part 1: general requirements.

Kato, K. and Hanai, T., 1998. The effect of backrest angles on discomfort caused by fore-andaft back vibration. Industrial Health, 36, 107-111.

Mistrot, P., Donati, P. and Galmiche, J.P., 1990. Assessing the discomfort of the whole-body multi-axis vibration: laboratory and field experiments. Ergonomics, 33 (12), 1523-1536.

Miwa, T., 1967. Evaluation methods for vibration effect. Part 1. Measurements of threshold and equal sensation contours of whole-body for vertical and horizontal vibrations. Industrial Health, 5, 183-204.

Miwa, T. and Yonekawa, Y., 1969. Evaluation methods for vibration effect. Part 9. Response to sinusoidal vibration at lying posture. Industrial Health, 7, 116-126. 
Miwa, T., Yonekawa, Y., and Kanada, K., 1984. Thresholds of perception of vibration in recumbent person. Journal Acoustical Society of America, 75 (3), 849-854.

Morioka. M. and Griffin, M.J., 2006. Magnitude-dependence of equivalent comfort contours for fore-and-aft, lateral and vertical whole-body vibration. Journal of Sound and Vibration, 298, 755-772.

Oborne, D.J. and Boarer, P.A., 1982. Subjective response to whole-body vibration - the effects of posture. Ergonomics, 25 (7),

Paddan, G.S. and Griffin, M.J., 1988. The transmission of the translational seat vibration to the head - I. Vertical seat vibration. Journal of Biomechanics, 21 (3), 191-197.

Parsons, K.C., Griffin, M.J. and Whitham, E.M., 1982. Vibration and comfort III. Translational vibration of the feet and back. Ergonomics, 25 (8), 705-719.

Pheasant, S., 1990. Bodyspace: Anthropometry, Ergonomics and the Design of Work. 2nd. ed., Taylor \& Francis.

Rebiffé, R., 1969. Seat of the driver: it's adaptation to functional and anthropometric requirements. Ergonomics, 12 (2), 246-261.

Shibata, N. and Maeda, S., 2009. Determination of backrest inclination based on biodynamic response study for prevention of low back pain. Medical Engineering \& Physics, 32, 577583.

Shoenberger, R.W. and Harris, C.S., 1971. Psychophysical assessment of whole-body vibration. Human Factors, 13, 41-50.

Shoenberger, R.W., 1988. Intensity judgements of vibrations in the $x$ axis, $z$ axis and $x$-plus-z axes. Aviation, Space and Environmental Medicine, 749-753.

Stevens, S.S., 1975. Psychophysics: Introduction to its perceptual, neural, and social prospects. New York: John Wiley \& Sons, Inc.

Szameitat, P. and Dupuis, H., 1976. "Über die beeinflussung des liegenden menschen durch mechanische schwingungen". Max-Planck Institut für Landarbeit und Landtechnik. Heft A-76-1, 1-116.

Toward, M.G.R.T. and Griffin, M.J., 2009. Apparent mass of the human body in the vertical vibration: Effect of seat backrest. Journal of Sound and Vibration, 327 (3-5), 657-669.

Wang, W., Rakheja, S. and Boileau, P-E., 2004. Effects of sitting posture on biodynamic response of seated occupants under vertical vibration. International Journal of Industrial Ergonomics, 34, 289-306.

Yonekawa, Y., Maeda, S., Kanada, K., and Takahashi, Y., 1999. Whole-body vibration perception thresholds of recumbent subjects - Part 1: supine posture. Industrial Health, 37, 398-403. 


\section{FIGURE LEGENDS}

Figure 1 Vertical whole-body vibration conditions: (a) with no backrest, (b) with upright backrest ( $0^{\circ}$-inclination), (c) with backrest inclined at $30^{\circ}$, (d) $60^{\circ}$, and (e) $90^{\circ}$ (recumbent).

Figure 2 Simplified schematic of model for predicting discomfort: showing two-stage procedure: weighting and combining procedure for measured accelerations at multiple-input locations (at seat, back and feet) for whole-body vertical vibration of seated people on a rigid seat.

Figure 3 Medians and inter-quartile ranges of the rates of growth of discomfort for vertical whole-body vibration within for each backrest condition (a-e), and comparison of the medians for all backrest conditions (f).

Figure 4 Medians and inter-quartile ranges of constant, $k$, for vertical seat vibration within each backrest condition (a-e), and comparison of the medians for all backrest conditions (f).

Figure $5 \quad$ Median equivalent comfort contours for seven magnitude estimates $(\psi=50$ to 200) where 100 corresponds to the discomfort caused by $0.4 \mathrm{~ms}^{-2}$ r.m.s. 8-Hz vertical wholebody vibration with the same backrest condition: (a) with no backrest, (b) with upright backrest $\left(0^{\circ}\right.$ - inclination), (c) with backrest inclined at $30^{\circ}$, (d) $60^{\circ}$, and (e) $90^{\circ}$ (recumbent), and the ranges of stimuli used.

Figure 6 Median relative discomfort for whole-body vertical vibration between backrest conditions: the contours indicate the vibration magnitudes required within each backrest inclination to produce a sensation magnitude of 100 for that produced by $0.4 \mathrm{~ms}^{-2}$ r.m.s. of 8$\mathrm{Hz}$ vertical whole-body vibration with no backrest condition (medians from 12 subjects).

Figure $7 \quad$ Principal locations of discomfort in the body caused by the middle and highest magnitude of vibration at each frequency of vertical whole-body vibration: (a) no backrest, (b) upright backrest $\left(0^{\circ}\right)$, (c), backrest inclined at $30^{\circ}$, (d) $60^{\circ}$, and (e) $90^{\circ}$ (recumbent).

Figure 8 Comparisons between median equivalent comfort contours for vertical wholebody vibration with no backrest and with backrest in the present study and as reported in earlier studies.

Figure 9 Comparisons between median equivalent comfort contours for vertical wholebody vibration with fully the reclined backrest in the present study and as reported in earlier studies.

Figure 10 Median component ride values and overall ride values calculated according to BS 6841 (1987) for exposures to vertical vibration of the vibrator platform required within each backrest condition to produce similar discomfort at each frequency to that when seated with no backrest. The reference (dotted line) shows an ideal prediction for each backrest condition, indicating similar values (inferring similar discomfort) at each frequency. (There are some 'overlaps' in the overall ride values calculated with the prediction method that uses the greatest component). 


\section{TABLE LEGEND}

Table 1 Median exponent $(n)$ and constant $(k)$ for vertical whole-body vibration with all backrest conditions: no backrest $(\mathrm{nb})$, upright backrest $\left(0^{\circ}\right)$, backrest inclined at $30^{\circ}, 60^{\circ}$ and fully reclined backrest $\left(90^{\circ}\right.$ or recumbent). 


\section{FIGURE 1}
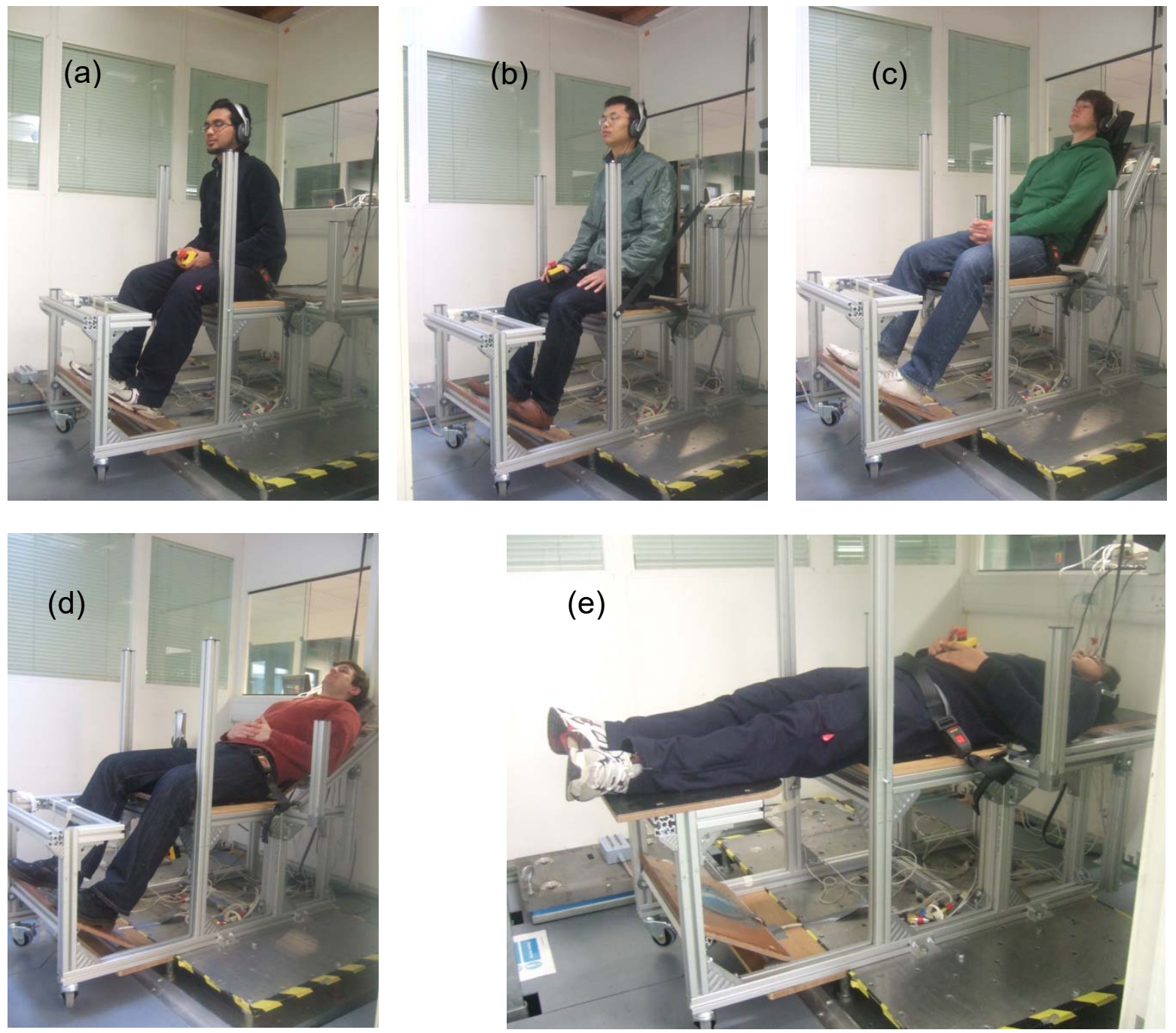


\section{FIGURE 2}

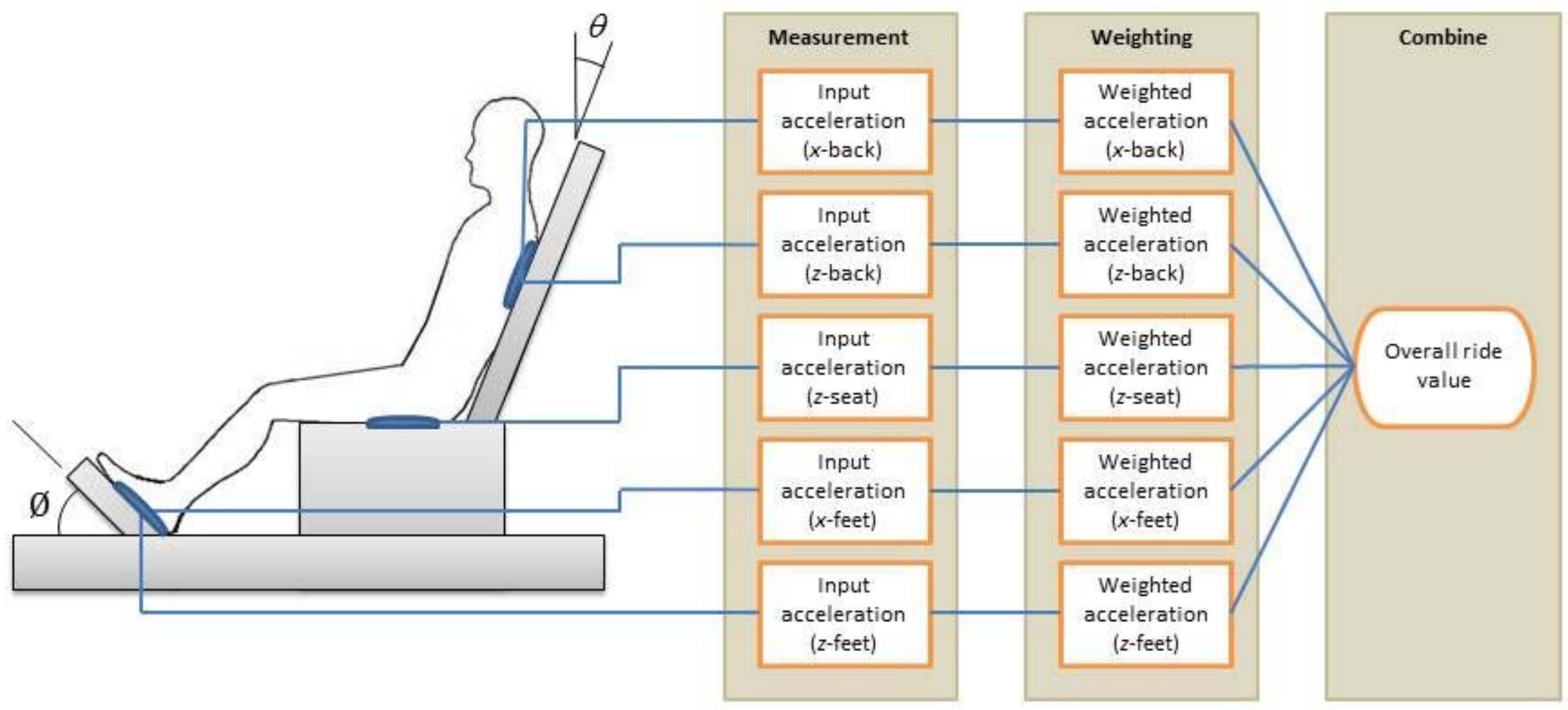


Published as: Predicting discomfort from whole-body vertical vibration when sitting with an inclined backrest Basri, B. \& Griffin, M. J. 2013 In : Applied Ergonomics. 44, 3, p. 423-434.

FIGURE 3 


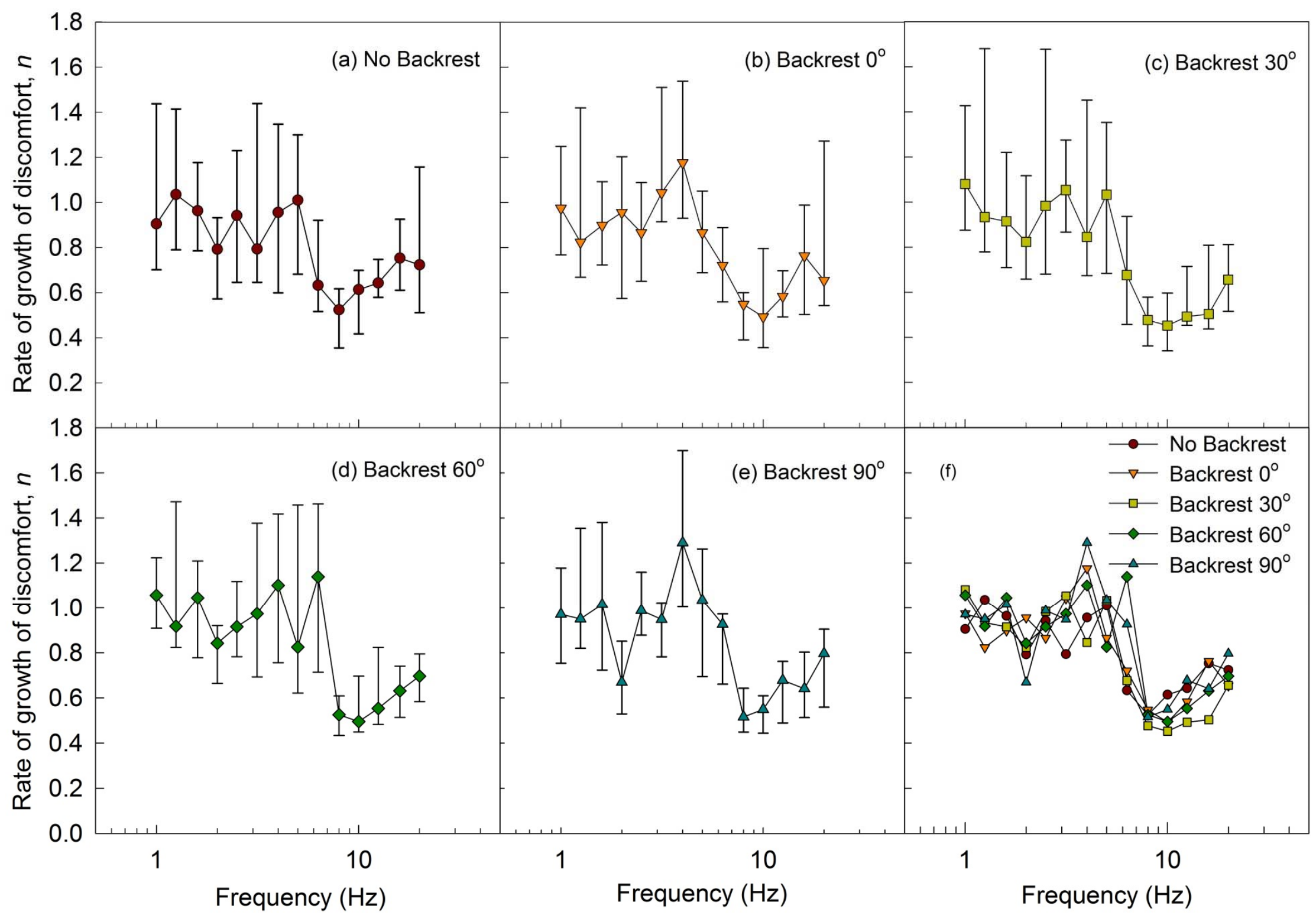


Published as: Predicting discomfort from whole-body vertical vibration when sitting with an inclined backrest Basri, B. \& Griffin, M. J. 2013 In : Applied Ergonomics. 44, 3, p. 423-434.

FIGURE 4 


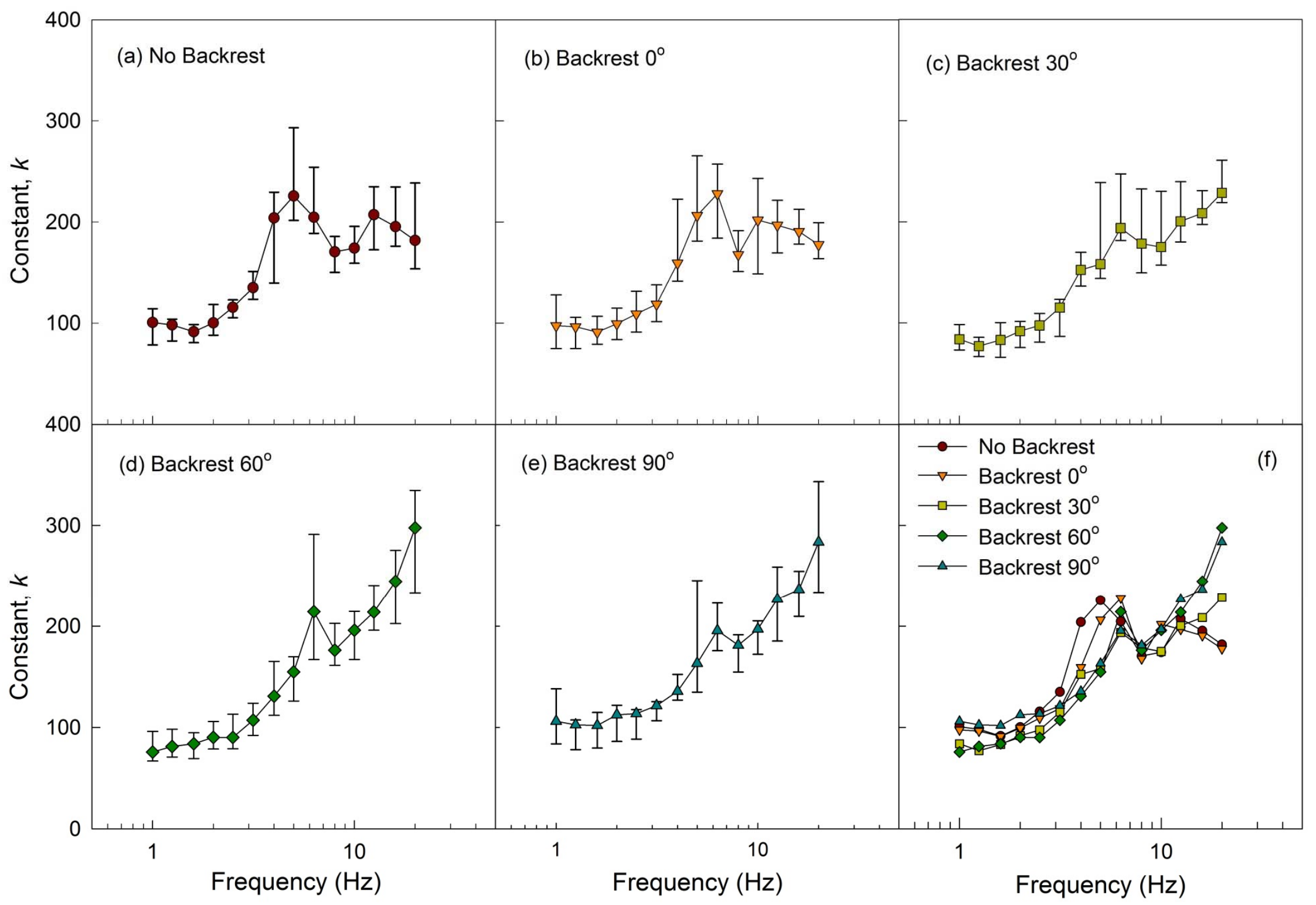


FIGURE 5

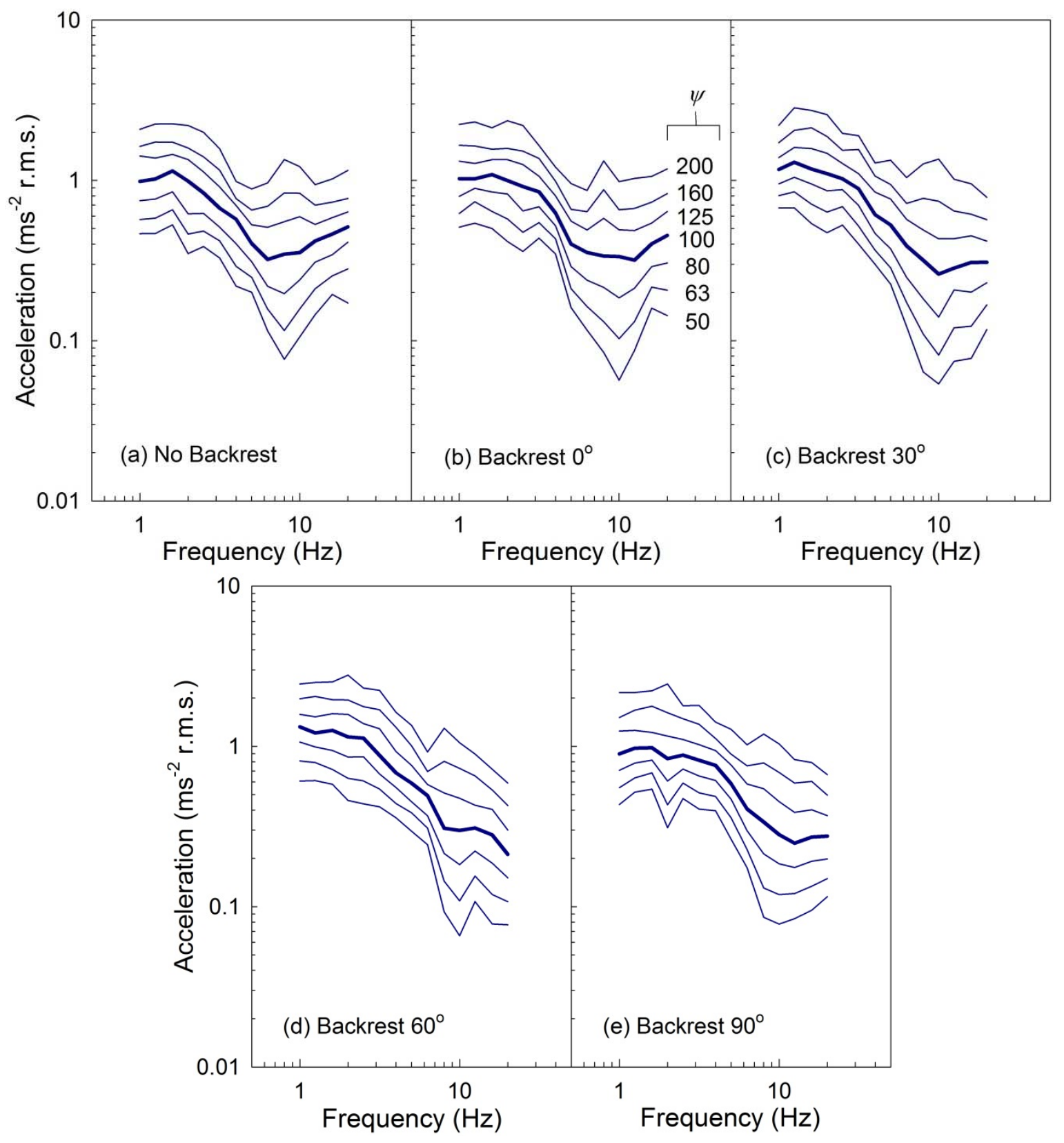


Published as: Predicting discomfort from whole-body vertical vibration when sitting with an inclined backrest Basri, B. \& Griffin, M. J. 2013 In : Applied Ergonomics. 44, 3, p. 423-434.

FIGURE 6 

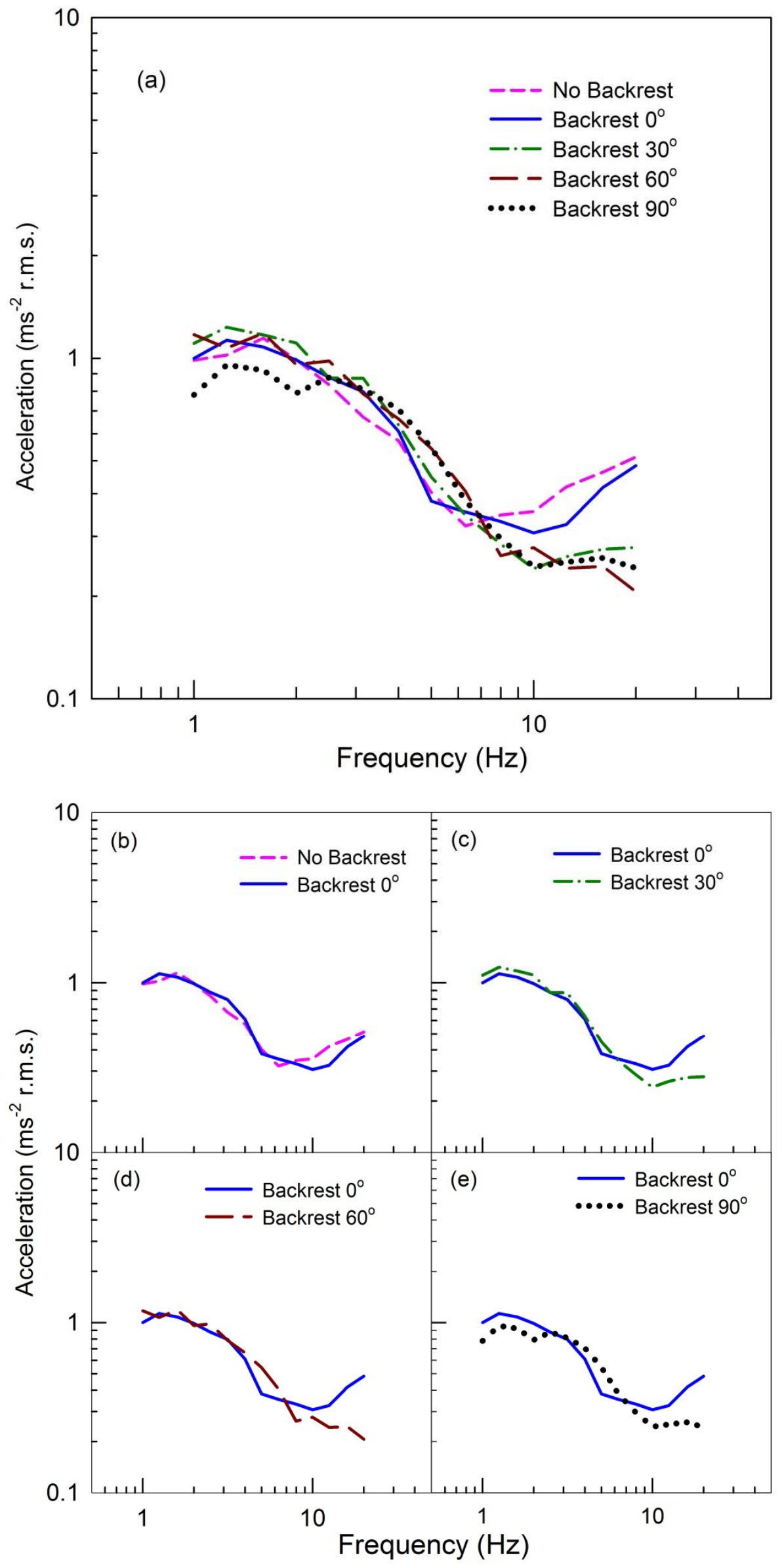


\section{FIGURE 7}
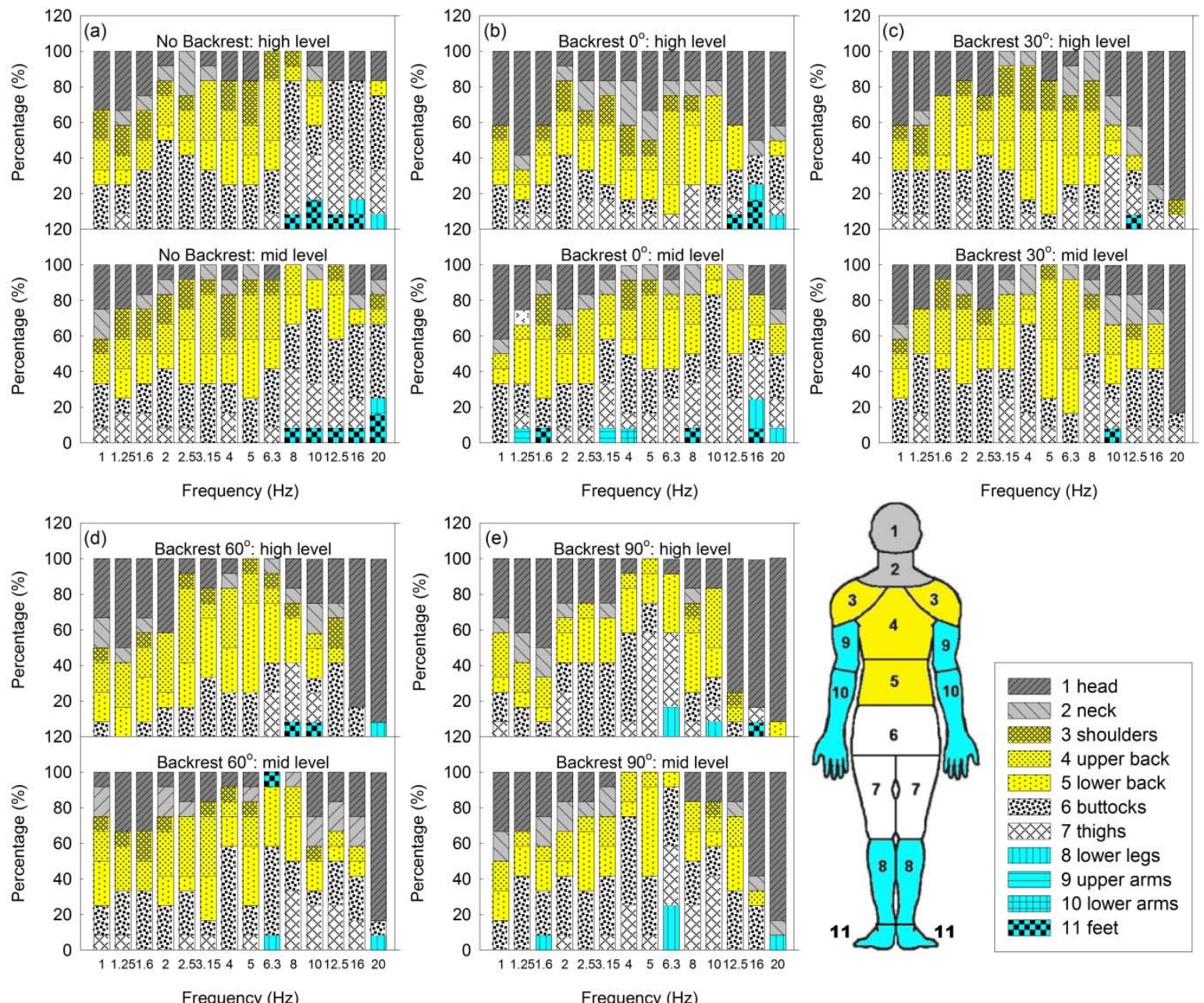

Frequency $(\mathrm{Hz})$

Frequency $(\mathrm{Hz})$ 


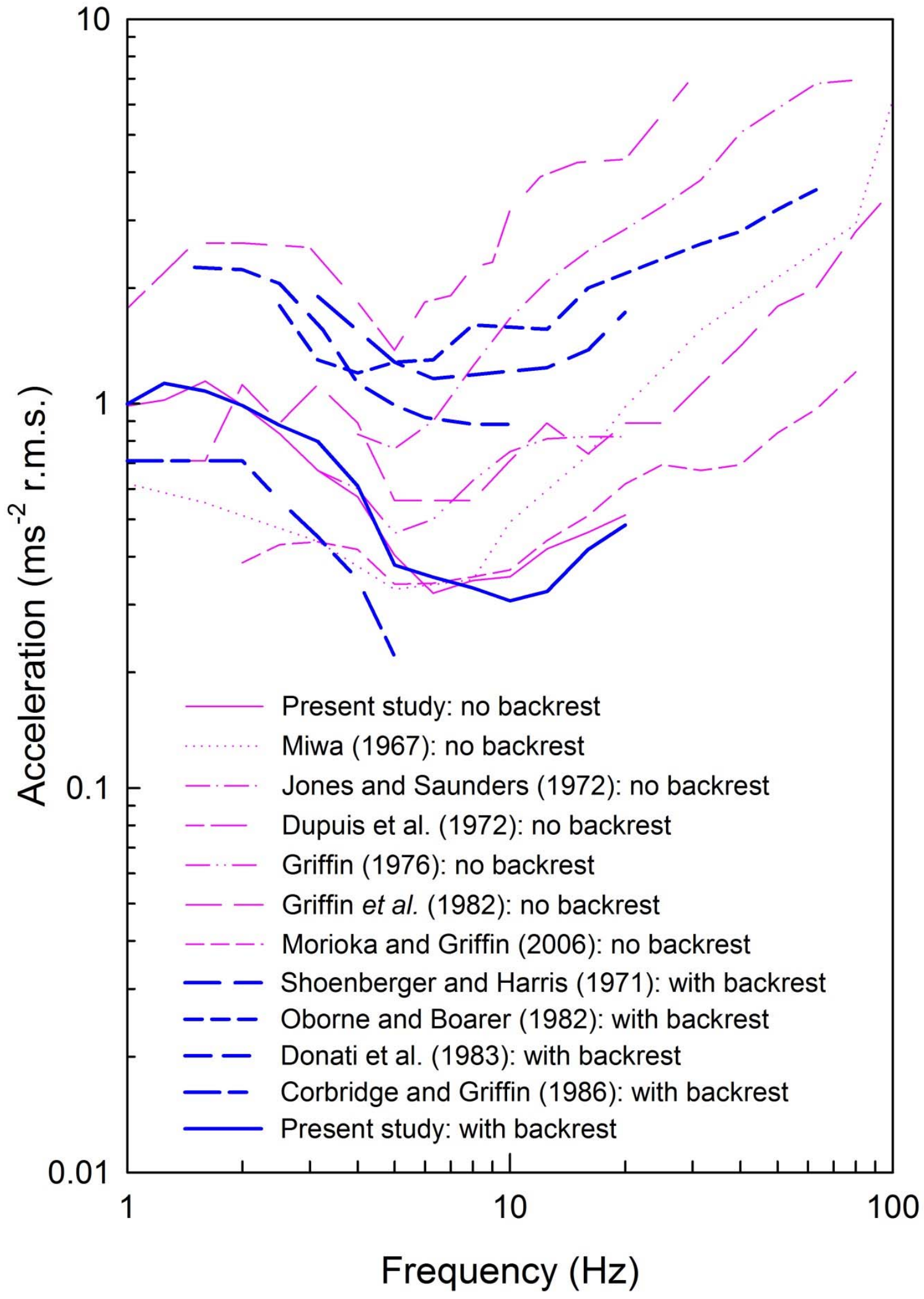


FIGURE 9

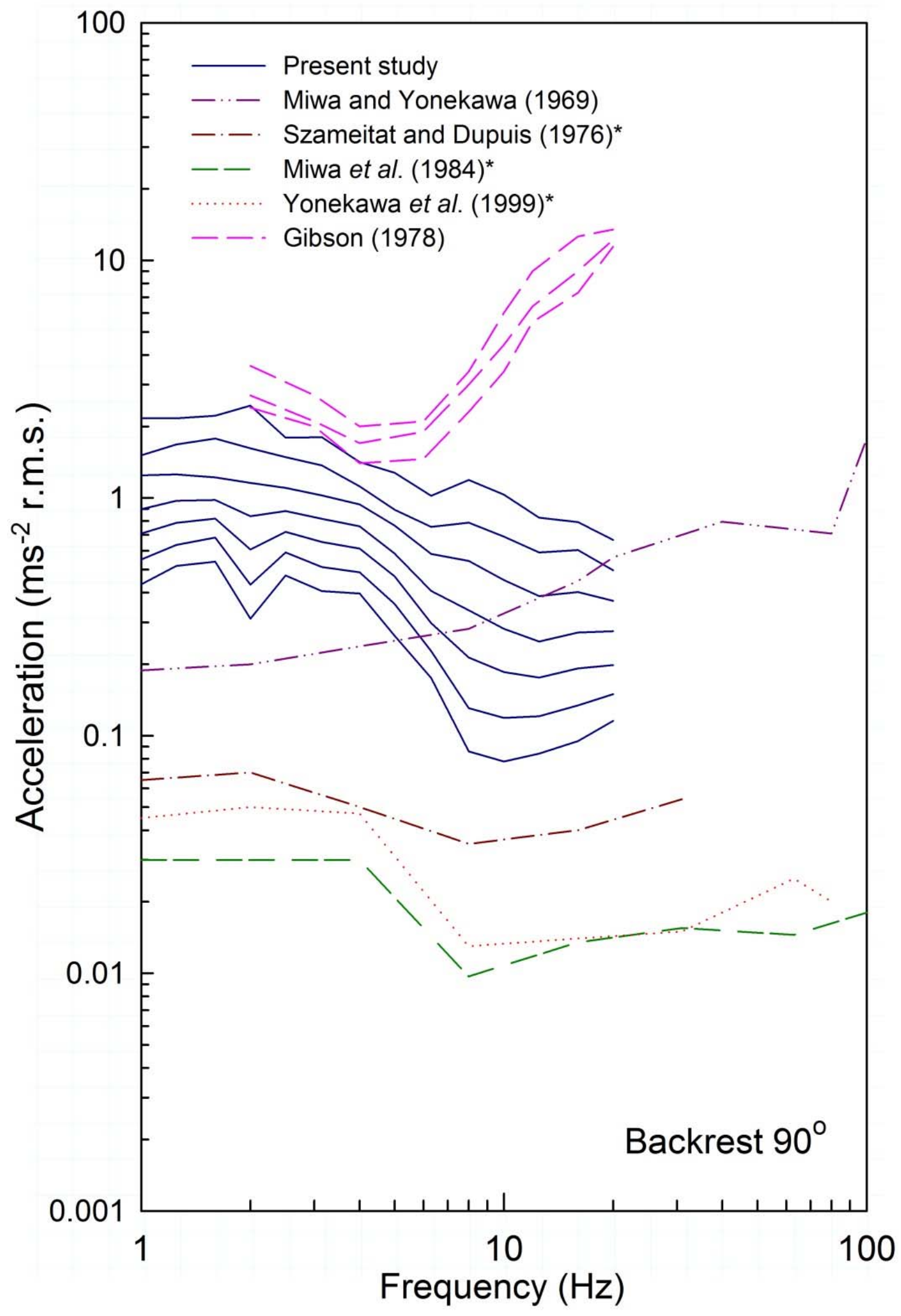




\section{FIGURE 10}
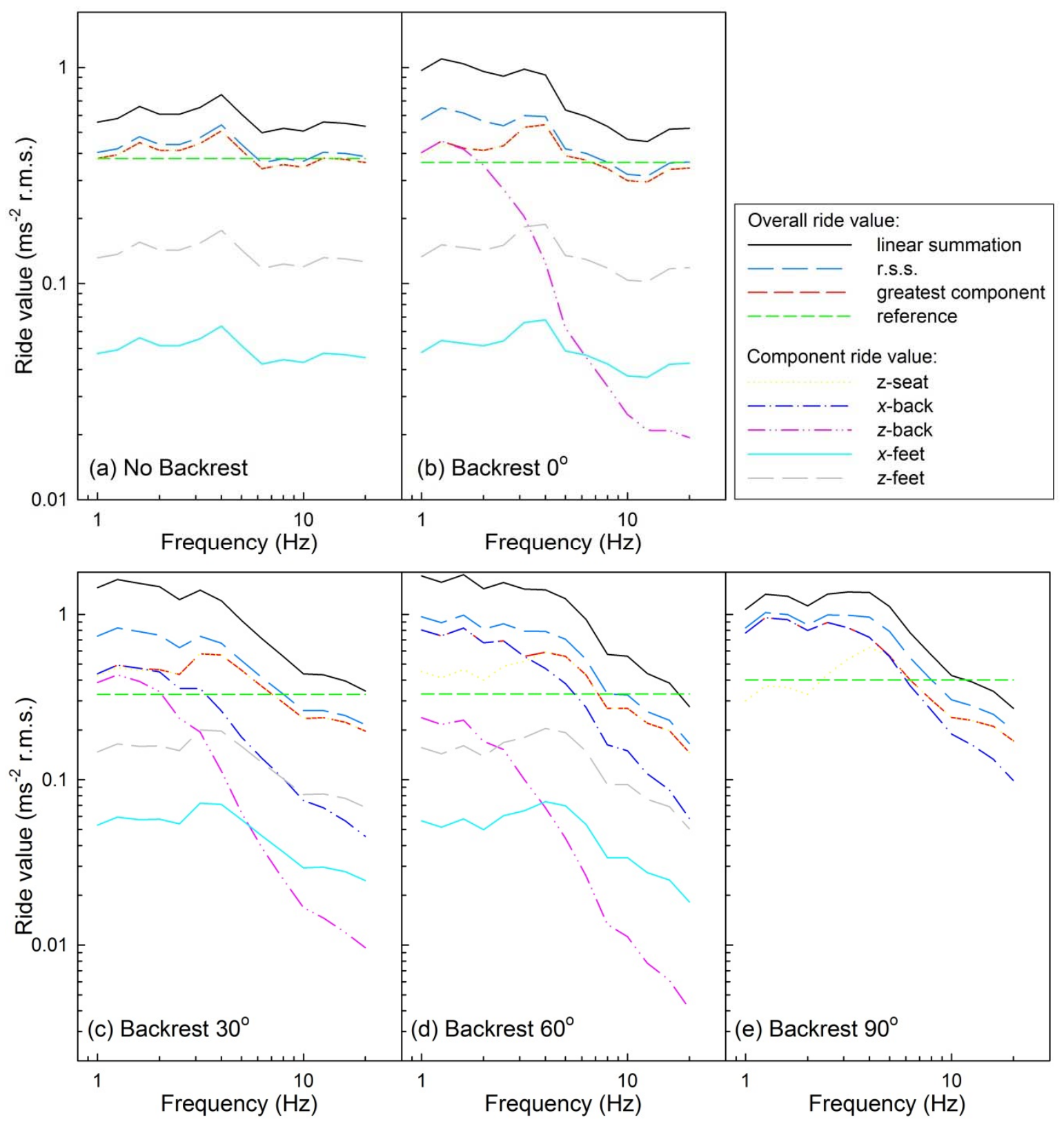


\begin{tabular}{|c|c|c|c|c|c|c|c|c|c|c|}
\hline \multirow{2}{*}{$\begin{array}{l}\text { Frequency } \\
\qquad(\mathrm{Hz})\end{array}$} & \multicolumn{5}{|c|}{ Exponent, $n$} & \multicolumn{5}{|c|}{ Constant, $k$} \\
\hline & $\mathrm{nb}$ & $0^{\circ}$ & $30^{\circ}$ & $60^{\circ}$ & $90^{\circ}$ & $\mathrm{nb}$ & $0^{\circ}$ & $30^{\circ}$ & $60^{\circ}$ & $90^{\circ}$ \\
\hline 1.0 & 0.905 & 0.974 & 1.081 & 1.057 & 0.971 & 100.6 & 97.5 & 83.8 & 75.7 & 106.1 \\
\hline 1.25 & 1.035 & 0.823 & 0.933 & 0.918 & 0.950 & 98.2 & 96.5 & 77.0 & 81.3 & 102.5 \\
\hline 1.6 & 0.963 & 0.898 & 0.915 & 1.045 & 1.015 & 91.4 & 91.1 & 83.1 & 83.9 & 101.9 \\
\hline 2.0 & 0.792 & 0.955 & 0.824 & 0.842 & 0.669 & 100.2 & 99.4 & 91.8 & 90.2 & 112.4 \\
\hline 2.5 & 0.942 & 0.865 & 0.984 & 0.915 & 0.988 & 115.7 & 109.2 & 97.5 & 90.0 & 113.6 \\
\hline 3.15 & 0.793 & 1.042 & 1.054 & 0.974 & 0.948 & 135.1 & 118.7 & 115.2 & 107.2 & 121.5 \\
\hline 4 & 0.955 & 1.176 & 0.845 & 1.100 & 1.290 & 203.9 & 159.3 & 152.3 & 130.9 & 135.6 \\
\hline 5 & 1.010 & 0.865 & 1.033 & 0.825 & 1.034 & 225.7 & 206.4 & 158.0 & 154.7 & 163.2 \\
\hline 6.3 & 0.633 & 0.720 & 0.676 & 1.138 & 0.926 & 204.6 & 227.9 & 193.7 & 214.3 & 195.6 \\
\hline 8 & 0.524 & 0.547 & 0.477 & 0.525 & 0.516 & 170.5 & 167.7 & 178.3 & 176.2 & 181.2 \\
\hline 10 & 0.614 & 0.493 & 0.452 & 0.495 & 0.549 & 174.1 & 201.9 & 174.9 & 195.8 & 197.0 \\
\hline 12.5 & 0.643 & 0.583 & 0.492 & 0.554 & 0.678 & 207.1 & 196.8 & 200.4 & 213.9 & 226.8 \\
\hline 16 & 0.753 & 0.763 & 0.503 & 0.631 & 0.641 & 195.4 & 190.5 & 208.5 & 244.5 & 236.4 \\
\hline 20 & 0.723 & 0.654 & 0.656 & 0.696 & 0.796 & 181.7 & 177.5 & 228.5 & 297.6 & 283.4 \\
\hline
\end{tabular}

